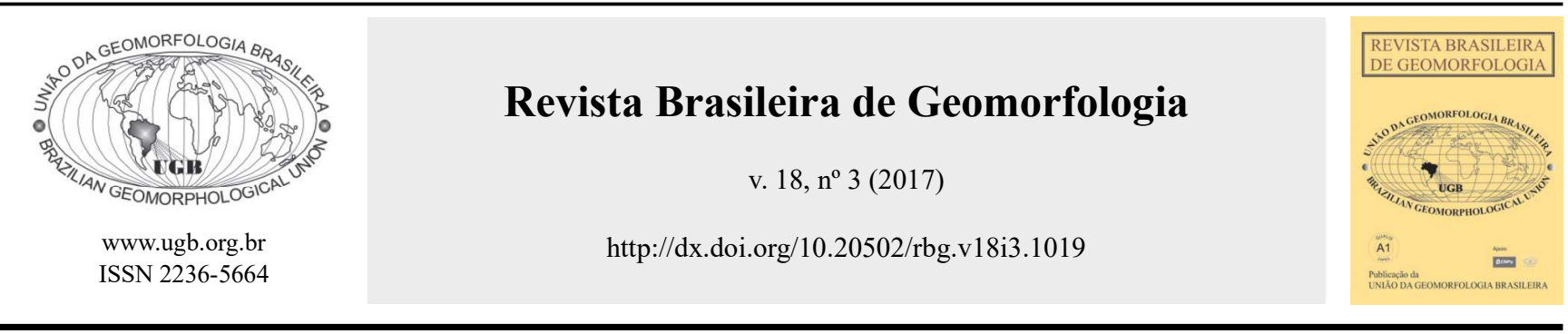

\title{
COMPARTIMENTAÇÃO FLUVIOMORFOMÉTRICA DA BACIA HIDROGRÁFICA DO RIO CHAPECÓ, PRIMEIRA APROXIMAÇÃO
}

\section{FLUVIOMORPHOMETRIC COMPARTIMENTATION IN THE RIVER BASIN CHAPECÓ, FIRST APPROACH}

\author{
Rafaela Harumi Fujita \\ Centro de Ciências Humanas, Universidade Estadual do Oeste do Paraná \\ Rua Maringá, 1200, Francisco Beltrão, Paraná. CEP: 85605-010. Brasil \\ Email: rafaela.fujita@gmail.com
}

Julio Cesar Paisani

Centro de Ciências Humanas, Universidade Estadual do Oeste do Paraná Rua Maringá, 1200, Francisco Beltrão, Paraná. CEP: 85605-010. Brasil

Email: juliopaisani@hotmail.com

Marga Eliz Pontelli

Centro de Ciências Humanas, Universidade Estadual do Oeste do Paraná Rua Maringá, 1200, Francisco Beltrão, Paraná. CEP: 85605-010. Brasil

Email:mepontelli@hotmail.com

\section{Informações sobre o Artigo}

Recebido (Received):

08/03/2016

Aceito (Accepted):

$10 / 03 / 2017$

\section{Palavras-chave:}

Rio Chapecó; Perfil

Longitudinal; Anomalias de

Drenagem; Compartimentação

Fluviomorfométrica.

\section{Keywords:}

Chapecó River; Longitudinal Profile; Drainage Anomalies;

Compatmentalizing

Fluviomorphometric.

\section{Resumo:}

O intuito desse trabalho foi compartimentar a bacia hidrográfica do rio Chapecó a partir de análises fluviomorfométricas, delineadas no perfil longitudinal e aplicação do índice de Hack ( gradient index). A área de estudo faz parte do sistema fluvial Uruguai e está localizada no Planalto das Araucárias, integralmente no estado de Santa Catarina. O rio Chapecó possui uma extensão de $425 \mathrm{~km}$ e altitudes que variam de 1300 a 240 $\mathrm{m}$, ao longo de seu perfil longitudinal apresenta trechos em equilíbrio e desajustes fluviais de ascensão e subsidência e várias rupturas de declive, que representam grande interesse geoturístico. Foram identificadas anomalias de $1^{\mathrm{a}}$ e $2^{\mathrm{a}}$ ordem ambas relacionadas a forte influencia estrutural. A presença das anomalias de $1^{\mathrm{a}}$ ordem nas regiões de saltos e cachoeiras, somadas as áreas de solos mais espessos remetem a processos neotectônicos. Como primeira aproximação a bacia do rio Chapecó foi dividida em 3 compartimentos $\mathrm{C} 1, \mathrm{C} 2$ e $\mathrm{C} 3$, sendo $\mathrm{C} 1$ e $\mathrm{C} 3$ blocos ascendentes e $\mathrm{C} 2$ um bloco subsidente. 


\section{Abstract:}

The purpose of this paper was compartmentalizing the basin Chapecó River from fluviomorphometric analysis, outlined in the longitudinal profile and application of the gradient index (Hack index). The study area is part of the Uruguay River system, located on the plateau of Aracaria, fully in the Santa Catarina state. The Chapecó River has a length og 425km and altitude ranging from 1300 to $240 \mathrm{~m}$, is longitudinal profile shows segments in the equilibrium and instability fluvial rise and subsidence and several slope ruptures, representing great interest geotouristic. Anomalies of 1 st and 2 nd order have been identified both related to strong structural influence. The presence of the 1st order anomalies in areas of jumps and waterfalls, together with areas of deeper soils refer to neotectonic processes. As a first approach to river basin Chapecó was divided into three compartments $\mathrm{C} 1, \mathrm{C} 2$ and $\mathrm{C} 3$, staying ascending blocks $\mathrm{C} 1$ and $\mathrm{C} 3$ and subsiding block, $\mathrm{C} 2$.

\section{Introdução}

Os canais fluviais são de grande importância para as análises de cunho tectônico por serem elementos sensíveis a modificações crustais, respondendo de imediato aos processos deformativos (ETCHEBEHERE, 2000). Uma das técnicas adotadas para a identificação de áreas influenciadas pela neotectônica são os índices morfométricos e os padrões de drenagem.

A análise morfométrica da rede de drenagem por meio de sua representação longitudinal pode ser uma ferramenta muito importante quando aliada a estudos geomorfológicos por atentar à compreensão dos condicionantes que equilibram ou desequilibram o sistema fluvial, bem como auxilia no entendimento da evolução geomorfológica de uma região (FUJITA, 2014) em escala temporal de milhar a dezenas de milhar de anos (TEIXEIRA et al., 2003).

De acordo com Knighton (1998) o perfil longitudinal é um elemento importante para o entendimento dos processos geomorfológicos que ocorrem na paisagem. O perfil longitudinal consiste num método simples e eficaz, que basicamente utiliza dados de altitude e extensão do canal, para a geração de uma curva de ajustamento logarítmico côncavo ascendente, onde se verificam maiores declividades nas nascentes e menores em direção à foz, sendo a representação gráfica característica de rios em estado de equilíbrio (FUJITA, 2009).

Um dos índices morfométricos utilizados para detectar áreas influenciadas por atividades tectônicas, é o índice de Hack. Em 1973 Hack propôs o índice de gradiente RDE (gradient index) para a determinação de "anomalias" significativas na concavidade natural do perfil longitudinal, o que também permitiu a normalização dos dados, o que facilitou para a comparação de canais fluviais de diferentes magnitudes.
Nos últimos anos o Planalto das Araucárias, especialmente os estados do Paraná e Santa Catarina, vêm sendo objeto de pesquisas voltados as geociências, sobretudo referente a gênese das formações superficiais e proxies ambientais para compreender a evolução do relevo (PAISANI et al., 2013). Com o desenvolvimento dos estudos suspeitou-se que os registros estratigráficos, encontrados nas bacias de baixa ordem dos rios Choppin -PR e Chapecó-SC, não eram exclusivamente de ordem paleoclimática. Assim, para suprir essa lacuna buscou-se desenvolver um estudo com o intuito de compreender a influência da tectônica regional para a evolução geomorfológica do Sistema Fluvial Uruguai, no tocante à bacia hidrográfica do rio Chapecó e deste estudo resultou a primeira aproximação de uma compartimentação fluviomorfométrica da bacia do rio Chapecó a qual é o escopo desse trabalho.

A bacia do rio Chapecó (Figura 1), faz parte do sistema fluvial Uruguai, encontra-se localizada no sul do Brasil, integralmente no estado de Santa Catarina, em uma zona subtropical, conforme a classificação de Köeppen apresenta dois tipos climáticos Cfa e Cfb, denominados de Mesotérmico úmido com verões quentes (Cfa) e Mesotérmico úmido com verões ameno (Cfb), as temperaturas médias e precipitações médias anuais que variam de 15 a $19^{\circ} \mathrm{C}$ e 1300 a $2300 \mathrm{~mm}$, respectivamente (PANDOLFO et al., 2002).

Compreende uma área de aproximadamente 8302 $\mathrm{km}^{2}$ e drena litologias do Grupo São Bento, que abrange as Formações Serra Geral e Paranapanema e as Fácies Chapecó, Caxias, Campos Novos e Campo Erê, e Depósitos Aluvionares (CPRM, 2014), estruturalmente é influenciada pelo Lineamento Taquara Verde e pelas Zonas de Falhas Lancinha-Cubatão, Caçador e Taxaquara (ZÁLAN et al., 1990), e encontra-se nos domínios das superfícies geomórficas descritas por Paisani et al. (2008). 


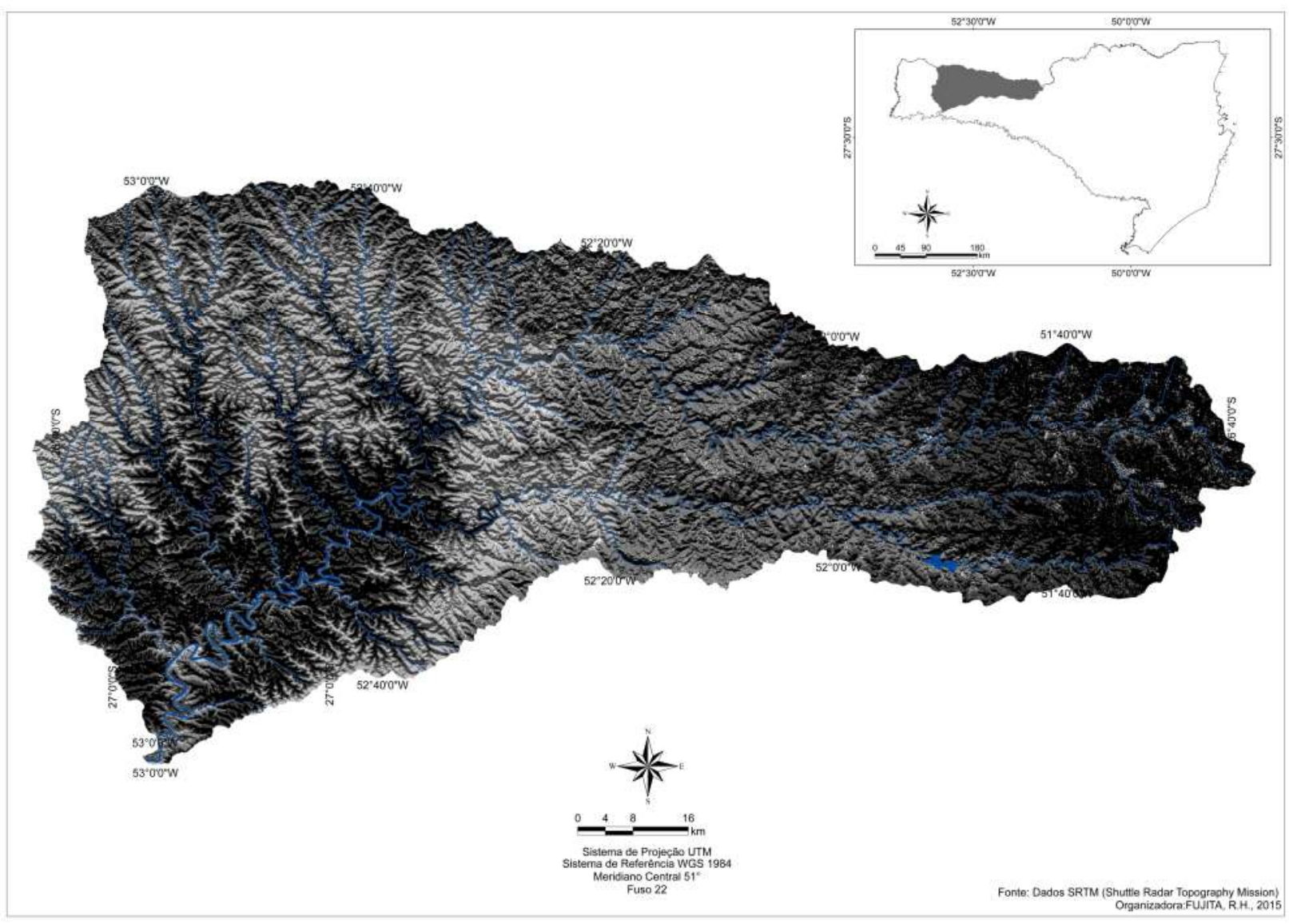

Figura 1- Mapa de localização da bacia do rio Chapecó, área em estudo

\section{Material e Métodos}

Para este estudo da influencia tectônica regional foi elaborado o perfil longitudinal do rio Chapecó. Para isto, foram utilizadas cartas topográficas do Exército Nacional e IBGE nas escalas de 1:100.000 e 1:50.000 e curvímetro analógico, além de dados SRTM (Shutter Radar Topographic Misson 4).

Os perfis longitudinais foram obtidos a partir de um gráfico, onde o eixo das coordenadas corresponderá as altitudes (m) e o eixo das abscissas a extensão do curso fluvial $(\mathrm{km})$. Para a análise do perfil longitudinal utilizou-se a metodologia mencionada por McKeown et al. (1988 apud ETCHEBEHERE,2000) a qual leva em consideração que todo curso fluvial procura o seu equilíbrio, sofrendo para isso erosão ou agradação seu próprio leito. Assim sendo, buscar-se determinar uma equação e uma linha de melhor ajuste ao perfil, a qual considerou anomalias os afastamentos superiores a 10 metros dessa linha. Trechos acima da linha de melhor ajuste foram considerados áreas ascendentes e abaixo desta, áreas subsidentes (Figura 2).
Para o cálculo do índice de gradiente (RDE) por trecho e em sua totalidade foi utilizada a metodologia descrita por Hack (1973), que engloba as seguintes equações:

$$
\text { RDE trecho }=(\mathrm{DH} / \mathrm{DL}) \times \mathrm{L}
$$

onde:

DH é a diferença altimétrica entre dois pontos selecionados do curso d'água;

DL é o comprimento do trecho analisado;

L corresponde à extensão acumulada do rio até o ponto médio do trecho onde o índice RDE está sendo calculado.

$$
\mathrm{RDE} \text { total }=(\mathrm{DH} / \mathrm{Lg} \mathrm{L})
$$

onde:

DH é a diferença altimétrica entre a cota superior e inferior do canal, ou seja, a diferença entre a cota localizada a montante do rio e a cota localizada na sua foz; Lg Lé o logaritmo natural da extensão total do curso d'água. 


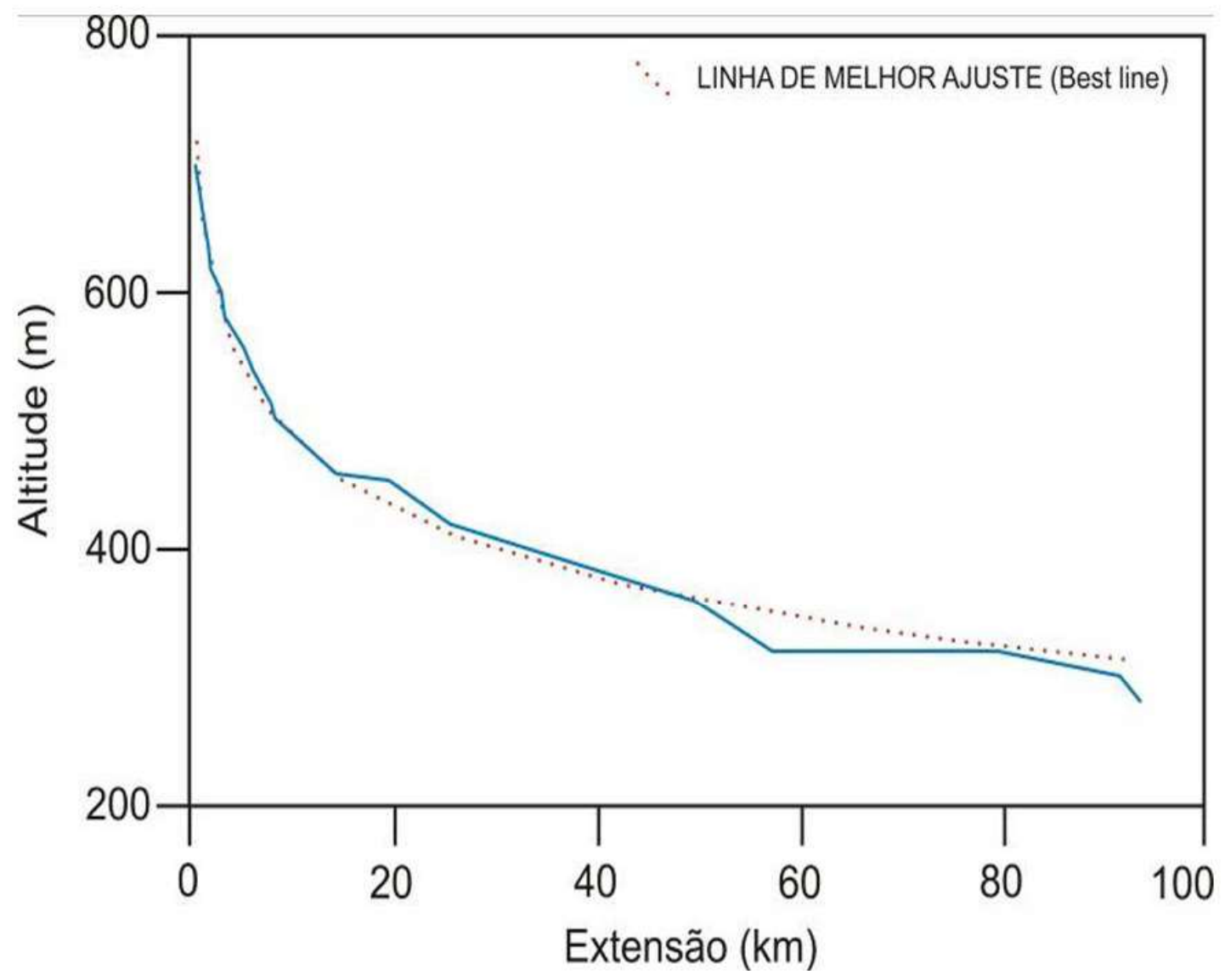

Figura 2 - Gráfico hipotético de um rio para demonstrar áreas com trechos anômalos (em ascensão - A e em subsidência-B), determinados em função da linha de ajuste

Para a determinação das anomalias de drenagem foi utilizada a razão entre $\mathrm{RDE}_{\text {Trecho }} / \mathrm{RDE}_{\text {Total }}$ Os valores compreendidos entre os limiares 2 e 10 corresponderão a anomalias de $2^{\mathrm{a}}$ ordem, já os valores superiores a 10 , anomalias de $1^{\mathrm{a}}$ ordem, conforme sugerido por Etchebehere (2000). Por fim, os resultados foram integrados a uma mapa geológico e de lineamentos estruturais e a partir dessa integração fora realizado uma compartimentação fluviomorfométrica da área de estudo.

\section{Resultados}

A bacia do rio Chapecó faz parte da bacia hidrográfica do rio Uruguai. Encontra-se localizado totalmente em terras catarinenses, ocupando uma área de $8302 \mathrm{~km}^{2}$. O rio Chapecó possui $425 \mathrm{~km}$ de extensão, de sua nascente nas imediações do município de Macieira até a sua foz junto ao rio Uruguai. As altitudes variam de 1300 a $240 \mathrm{~m}$, o que representa uma amplitude de relevo de $1060 \mathrm{~m}$ (Figura 3).
Seu perfil revela um desajuste em relação à curva côncava de um rio equilibrado, de nascente à foz, nele podem-se distinguir áreas em ascensão (convexa) e subsidência (côncava).

O segmento em ascensão localiza-se entre os quilômetros 10 a $240 \mathrm{~km}$ e a área em subsidência está localizada entre os quilômetros 240 a $425 \mathrm{~km}$. O rio Chapecó no segmento em ascensão possui maior energia de relevo, neste trecho apresenta inúmeros ressaltos topográficos, que representam várias quedas d'água e cachoeiras, como por exemplo as Cataratas do rio Chapecó, localizadas no município de Abelardo Luz (Figura 4). A partir da altitude de 700 m, $192 \mathrm{~km}$ de extensão, o rio Chapecó apresenta um longo trecho côncavo até sua desembocadura com o rio Uruguai na altitude de $240 \mathrm{~m}(425 \mathrm{~km})$. É neste trecho que se verifica a desembocadura do rio Chapecozinho, seu principal afluente. 
Compartimentação Fluviomorfométrica da Bacia Hidrográfica do Rio Chapecó, Primeira Aproximação

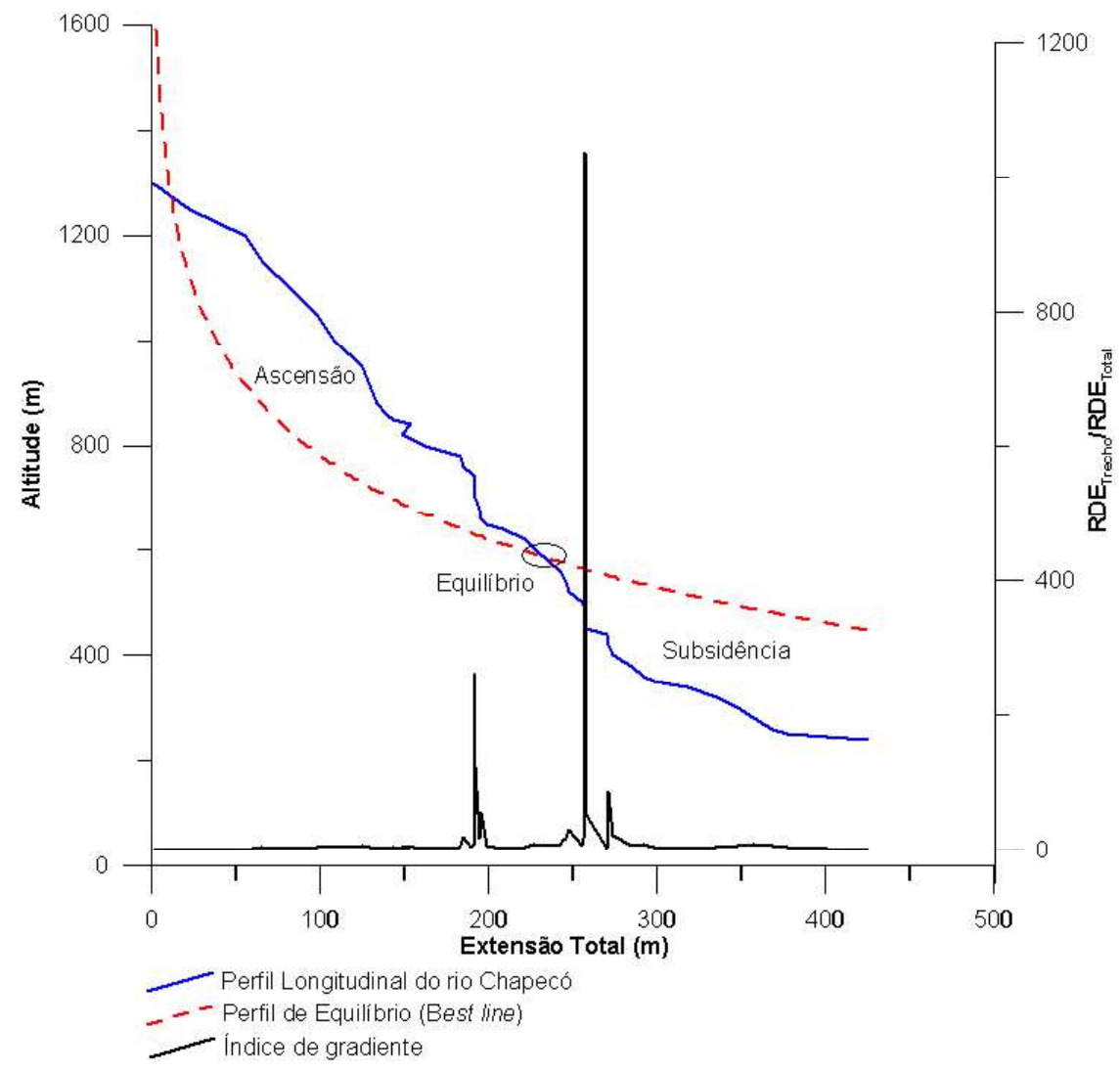

Figura 3 - Perfil longitudinal do rio Chapecó. Onde: Perfil de equilíbrio (Best line): $Y=-230.1133328 * \ln (X)+1840.421339$

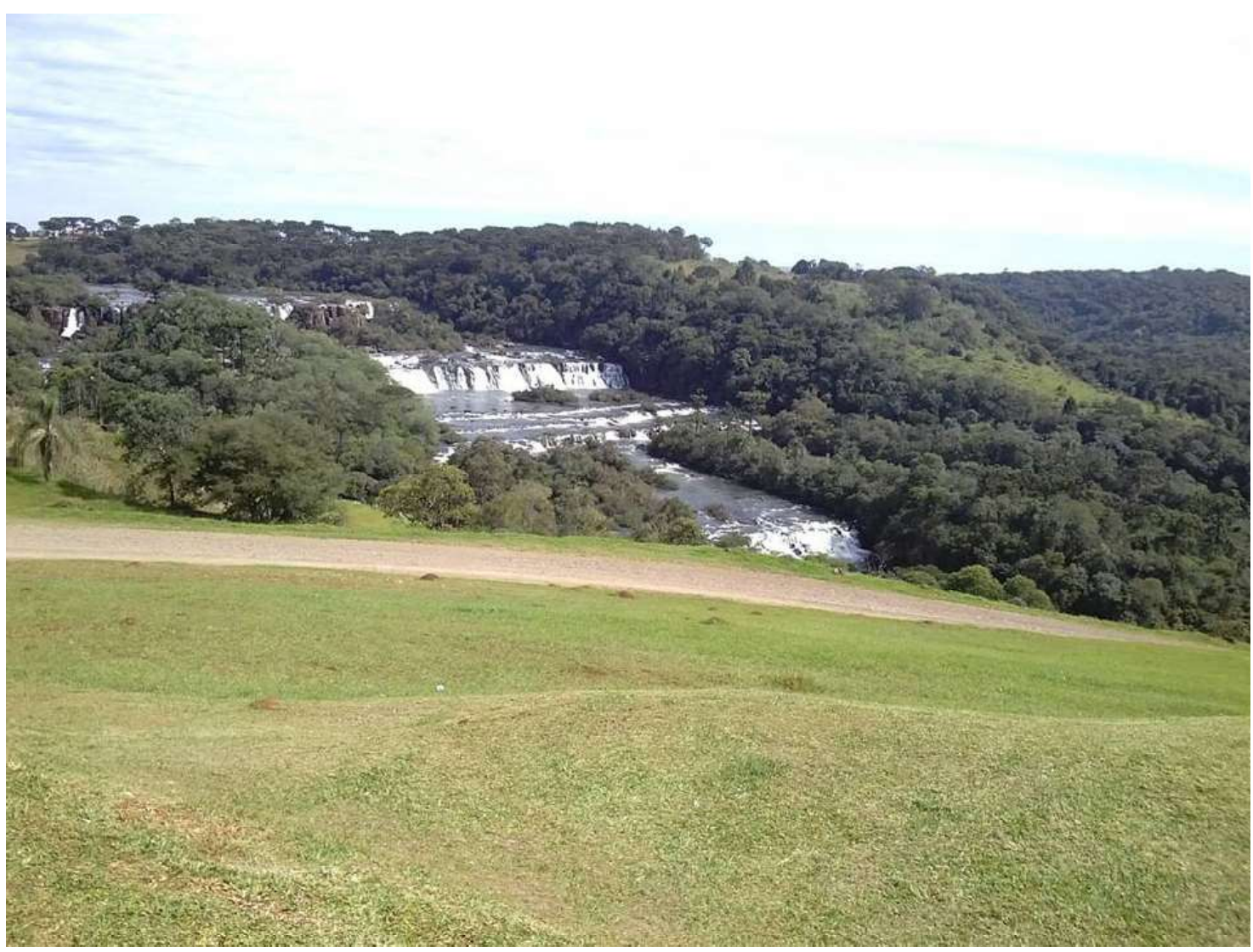

Figura 4 - Ao fundo as Cataratas do rio Chapecó, localizada no município de Abelardo Luz-SC. 
O rio Chapecó apresentou 44 trechos com índices RDE anômalos em 48 trechos mensurados. (Tabela 1). Entre as cotas 1300 a $1050 \mathrm{~m}$ e na altitude $240 \mathrm{~m}$ o rio Chapecó apresenta trechos em equilíbrio, com índices de RDE inferiores a 2. Os trechos anômalos estão distribuídos entre as cotas 1050 a $240 \mathrm{~m}$. Os mais expressivos valores de RDE 260,7, 123,9 e 518,7 foram identificados nos segmentos compreendidos pelas cotas 720 a $680 \mathrm{~m}$ e 460 a $450 \mathrm{~m}$, respectivamente.

Tabela 1: Tabela resumo das variáveis morfométricas do Rio Chapecó. Onde: RDE $_{\text {Total }} \mathbf{8 1 , 7 9 9 4 .}$

\begin{tabular}{|c|c|c|c|c|c|c|c|}
\hline Trecho & $\begin{array}{c}\text { Cota } \\
\text { Superior } \\
(\mathbf{m})\end{array}$ & $\begin{array}{c}\text { Cota } \\
\text { Inferior } \\
\text { (m) }\end{array}$ & $\begin{array}{c}\text { Ext. } \\
\text { Trecho } \\
\text { (m) }\end{array}$ & $\begin{array}{c}\text { Ext. Total } \\
(\mathbf{k m})\end{array}$ & $\begin{array}{l}\text { Declividade } \\
(\mathrm{m} / \mathrm{m})\end{array}$ & $\mathbf{R D E}_{\text {TRECHO }}$ & $\begin{array}{c}\mathbf{R D E}_{\text {TRECHO }} / \\
\mathbf{R D E}_{\text {TOTAL }}\end{array}$ \\
\hline 1 & 1300 & 1250 & 822,81 & 822,81 & 0,060767 & 1,386104 & 0,016945 \\
\hline 2 & 1250 & 1200 & 21885 & 22707,81 & 0,002285 & 50,05211 & 0,611889 \\
\hline 3 & 1200 & 1150 & 32710 & 55417,81 & 0,001529 & 83,48794 & 1,020642 \\
\hline 4 & 1150 & 1100 & 10213 & 65630,81 & 0,004896 & 317,3936 & 3,880146 \\
\hline 5 & 1100 & 1050 & 17314 & 82944,81 & 0,002888 & 237,2208 & 2,900031 \\
\hline 6 & 1050 & 1000 & 14981 & 97925,81 & 0,003338 & 324,1633 & 3,962906 \\
\hline 7 & 1000 & 950 & 10565 & 108490,8 & 0,003338 & 359,4246 & 4,393977 \\
\hline 8 & 950 & 880 & 16804 & 125294,8 & 0,004166 & 518,6049 & 6,33996 \\
\hline 9 & 880 & 860 & 8497 & 133791,8 & 0,002354 & 313,0324 & 3,82683 \\
\hline 10 & 860 & 850 & 5625 & 139416,8 & 0,001778 & 246,4299 & 3,012613 \\
\hline 11 & 850 & 840 & 4160 & 143576,8 & 0,002404 & 343,2135 & 4,195795 \\
\hline 12 & 840 & 820 & 9805 & 153381,8 & 0,00204 & 311,2327 & 3,804828 \\
\hline 13 & 820 & 800 & 4808 & 148384,8 & 0,00416 & 613,9135 & 7,505111 \\
\hline 14 & 800 & 780 & 14010 & 162394,8 & 0,001428 & 230,685 & 2,82013 \\
\hline 15 & 780 & 760 & 20671 & 183065,8 & 0,000968 & 176,3493 & 2,155875 \\
\hline 16 & 760 & 750 & 2313 & 185378,8 & 0,008647 & 798,0061 & 9,755648 \\
\hline 17 & 750 & 740 & 4329 & 189707,8 & 0,00231 & 436,3775 & 5,334727 \\
\hline 18 & 740 & 720 & 2102 & 191809,8 & 0,004757 & 1817,41 & 22,21789 \\
\hline 19 & 720 & 700 & 179,3 & 191989,1 & 0,111545 & 21326,17 & 260,713 \\
\hline 20 & 700 & 680 & 378,07 & 192367,2 & 0,0529 & 10133,95 & 123,8879 \\
\hline 21 & 680 & 660 & 2708 & 195075,2 & 0,007386 & 1434,824 & 17,54077 \\
\hline 22 & 660 & 650 & 840 & 195915,2 & 0,02381 & 2322,8 & 28,39629 \\
\hline 23 & 650 & 640 & 3385 & 199300,2 & 0,002954 & 586,4112 & 7,168894 \\
\hline 24 & 640 & 620 & 8837 & 208137,2 & 0,001132 & 469,2479 & 5,736569 \\
\hline 25 & 620 & 600 & 13729 & 221866,2 & 0,001457 & 322,0427 & 3,936981 \\
\hline 26 & 600 & 580 & 5579 & 227445,2 & 0,003585 & 812,4939 & 9,932762 \\
\hline 27 & 580 & 560 & 8293 & 235738,2 & 0,002412 & 566,5939 & 6,926628 \\
\hline 28 & 560 & 550 & 6653 & 242391,2 & 0,003006 & 363,1312 & 4,439289 \\
\hline 29 & 550 & 540 & 1828 & 244219,2 & 0,00547 & 1331,615 & 16,27903 \\
\hline 30 & 540 & 520 & 1656 & 245875,2 & 0,006039 & 2959,845 & 36,18419 \\
\hline 31 & 520 & 500 & 1920 & 247795,2 & 0,010417 & 2572,866 & 31,45337 \\
\hline 32 & 500 & 480 & 7900 & 255695,2 & 0,002532 & 645,3043 & 7,888863 \\
\hline 33 & 480 & 460 & 2090 & 257785,2 & 0,009569 & 2459,188 & 30,06365 \\
\hline 34 & 460 & 450 & 60,583 & 257845,8 & 0,330126 & 42428,7 & 518,692 \\
\hline 35 & 450 & 440 & 605,36 & 258451,1 & 0,016519 & 4256,164 & 52,03172 \\
\hline 36 & 440 & 420 & 11867 & 270318,1 & 0,000843 & 454,2313 & 5,552991 \\
\hline 37 & 420 & 400 & 748 & 271066,1 & 0,026738 & 7226,367 & 88,34255 \\
\hline 38 & 400 & 380 & 3113 & 274179,1 & 0,006425 & 1756,371 & 21,47168 \\
\hline 39 & 380 & 360 & 10751 & 284930,1 & 0,00186 & 528,565 & 6,461723 \\
\hline 40 & 360 & 350 & 6976 & 291906,1 & 0,002867 & 417,2966 & 5,101463 \\
\hline 41 & 350 & 340 & 6242 & 298148,1 & 0,001602 & 476,3667 & 5,823597 \\
\hline 42 & 340 & 320 & 19868 & 318016,1 & 0,000503 & 319,3237 & 3,903741 \\
\hline 43 & 320 & 300 & 17111 & 335127,1 & 0,001169 & 390,7745 & 4,77723 \\
\hline 44 & 300 & 280 & 12820 & 347947,1 & 0,00156 & 541,5712 & 6,620723 \\
\hline 45 & 280 & 260 & 9272 & 357219,1 & 0,002157 & 768,8074 & 9,398693 \\
\hline 46 & 260 & 250 & 11561 & 368780,1 & 0,00173 & 318,2944 & 3,891158 \\
\hline 47 & 250 & 240 & 8367 & 377147,1 & 0,001195 & 449,7994 & 5,49881 \\
\hline 48 & 240 & 240 & 47295 & 424442,1 & 0,000211 & 0 & 0 \\
\hline
\end{tabular}




\section{Compartimentação Fluviomorfométrica da Bacia Hidrográfica do Rio Chapecó, Primeira Aproximação}

A distribuição dos índices de $\mathrm{RDE}$ ao longo do rio Chapecó exibe concentrações no médio e baixo curso do rio (Figura 5). No alto rio Chapecó, afloram rochas da Formação Serra Geral onde se encontram os menores valores de RDE. Por sua vez, onde predominam as Fácies Campos Novos, Chapecó e Paranapanema, encontram-se os maiores valores detectados. As anomalias de $1^{\mathrm{a}}$ ordem identificados no rio Chapecó coincidem com fortes rupturas de declive no perfil longitudinal, muitas delas aproveitadas para a geração de energia elétrica.

Ao analisar a bacia do rio Chapecó, verifica-se a que a montante do Domo de Vargeão a bacia se caracteriza por ser alongada e de vertentes curtas, ao se aproximar do astroblema muda significantemente. A drenagem começa a apresentar padrões complexos, denotando controle estrutural. Podemos verificar que o rio Chapecó se encaixa em falhas/fraturas, mudando seu curso preferencial dando um aspecto arqueado para a drenagem, isso também ocorre para seu afluente principal, o rio Chapecozinho. Após a desembocadura do rio Chapecozinho, a bacia do rio Chapecó muda sua configuração novamente, tornando-se bem assimétrica, com flanco direito mais prolongado que o esquerdo, fazendo com que os afluentes da, margem direita sejam mais extensos.

Ao espacializarmos as anomalias de drenagem comparando com a distribuição dos solos na bacia do rio Chapecó (Figura 6) as anomalias de $1^{\mathrm{a}}$ ordem se concentram nas regiões que predominam solos mais espessos (latossolos e cambissolos). Já os segmentos classificados como equilíbrio, localizam-se em áreas que predominam cambissolos e solos litólicos. Por sua vez, anomalias de $2^{\mathrm{a}}$ ordem são distribuídas ao longo de áreas com cambissolos e latossolos.

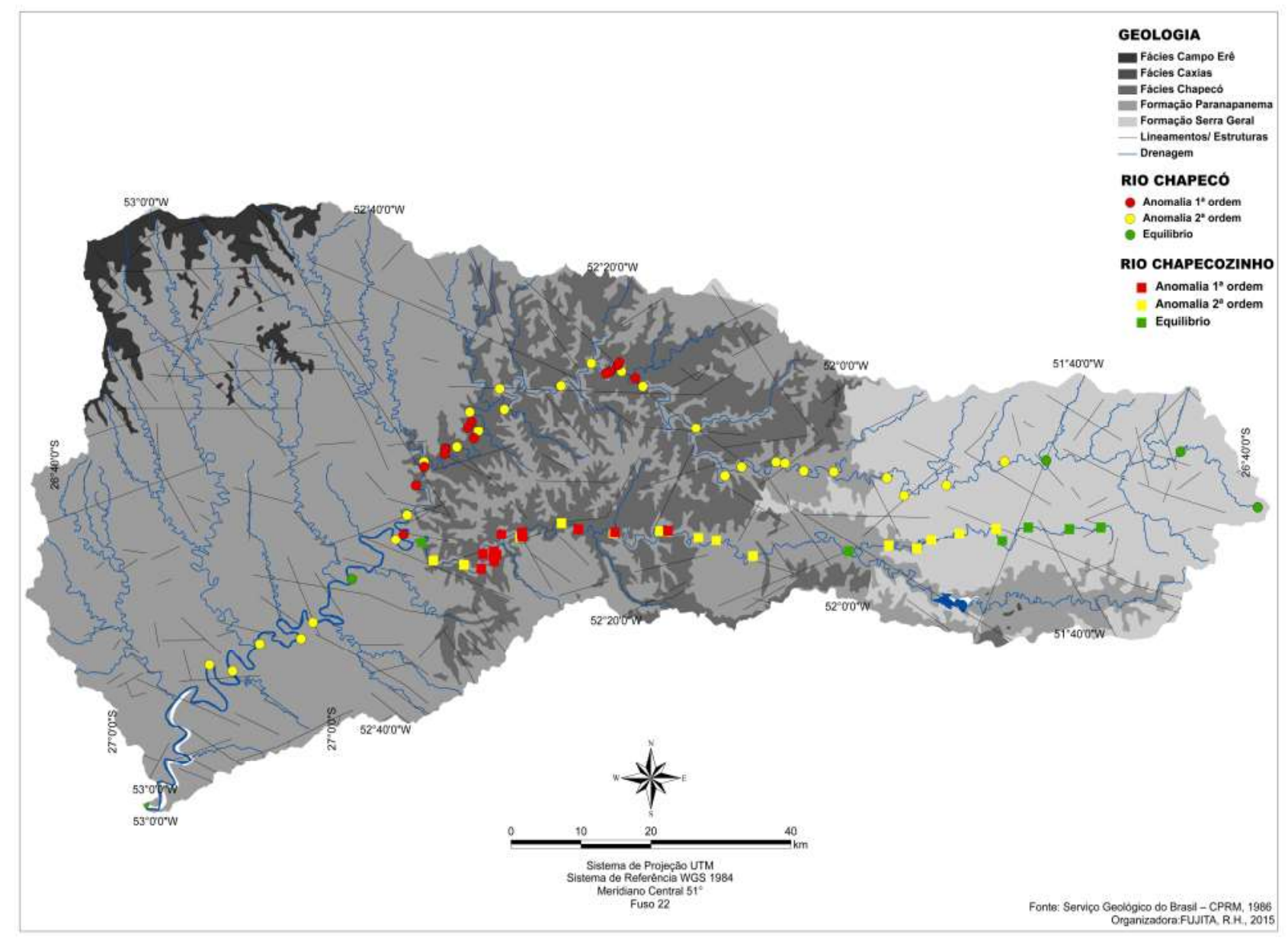

Figura 5- Espacialização das anomalias de drenagem na bacia do rio Chapecó 


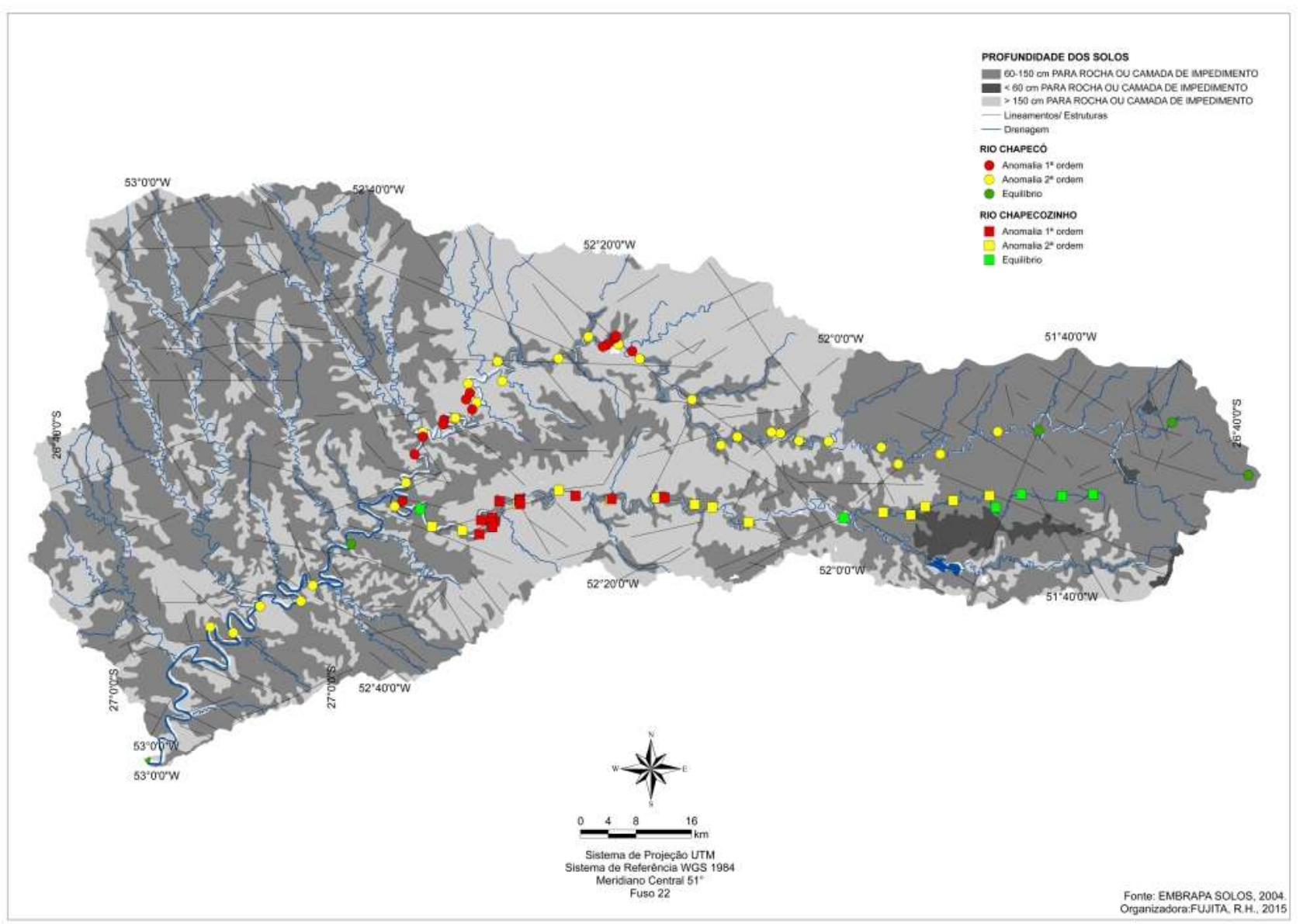

Figura 6 - Mapa de profundidade dos solos da bacia hidrográfica do rio Chapecó.

\section{Discussão}

O perfil longitudinal do rio Chapecó encontra-se em desajuste fluvial de nascente a foz, podendo ser distinguido trechos convexo e côncavo em sua extensão e inúmeras rupturas de declive (knickpoints) que juntas chegam a apresentar aproximadamente 100 $\mathrm{m}$ de amplitude. Estas rupturas indicam alterações no equilíbrio do curso d'água nesses trechos que podem estar relacionados à existência de substratos rochosos mais resistentes (mudança de nível de base local), confluência com afluentes de caudal expressivo, atividade neotectônica \{Seeber \& Gortnitz (1983), McKeown et al. (1988), Martinez (2004), Guedes et al. (2006)\}, atividades antrópicas (LARUE, 2008) entre outros. Essas rupturas podem ser consideradas como geossítios (SALAMUNI et al., 2013) áreas de grande interesse geoturístico, como é o caso das Cataratas do rio Chapecó, localizada no município de Abelardo Luz.

Como verificado, por meio de imagens de satélite e checagem em campo, nas rupturas de declive ocor- rem a presença de quedas d'água (cachoeiras), muitas delas aproveitadas para geração de energia elétrica, e a entrada de afluentes ao longo do rio Chapecó. Bartorelli (1997) comenta que a formação de cachoeiras, na Bacia Sedimentar do Paraná, deve-se a diferenças na resistência das rochas, onde camadas de rochas mais resistentes sobrepostas a rochas mais friáveis propiciam esse desenvolvimento, na bacia em estudo nas Fácies Paranapanema, Chapecó e Campos Novos é que se verificam as principais e mais relevantes quedas d'água.

De acordo com Etchebehere (2000), Aclas Jr et al. (2003), Guedes et al. (2006) e Guedes (2008), Fujita et al. (2011), Fujita (2014), os desajustes fluviais e anomalias de $2^{\mathrm{a}}$ ordem ocorrem associados a áreas marcadas por mudanças litológicas, controle estrutural, encontro de canais fluviais. As anomalias de $2^{\mathrm{a}}$ ordem diagnosticadas na área em estudo estão vinculadas a um controle estrutural, marcado por falhas e fraturas, pelo astroblema de Vargeão e representado pela configuração da drenagem, e pela confluência dos canais, o que permi- 


\section{Compartimentação Fluviomorfométrica da Bacia Hidrográfica do Rio Chapecó, Primeira Aproximação}

te a modificação da vazão, nas texturas granulométricas (CARLSTON, 1969).

As anomalias de $1^{\text {a }}$ ordem detectadas sugerem forte controle estrutural, já ressaltado anteriormente. A presença dessas anomalias associadas a regiões de saltos e quedas d'água, indicam a configuração de uma área tectonicamente ativa, relacionada a processos neotectônicos de soerguimento. Configurações semelhantes a da bacia do rio Chapecó, foram verificadas para o Rio do Peixe ( ETCHEBEHERE, 2000, ETCHEBEHERE et al. (2004)) e para o Rio dos Patos (FUJITA et al., 2011).

Ao comparar as espessuras das formações superficiais com as anomalias de drenagem verificou-se que as anomalias se concentram em áreas que possuem maiores espessuras para a camada de impedimento e/ ou rocha. Santos et al. (2011) utilizaram de técnicas fluviomorfométricas comparando-as com as espessuras de solo para executar uma análise de prováveis deformações tectônicas para a região do Paranapanema, uma área de tectônica muito sutil. Em seu estudo, o autor verificou que as áreas mais dissecadas correspondem a trechos com movimentações ascensionais, que resultam solos mais rasos. Já em áreas com solos espessos, verificam-se áreas anômalas e que representam blocos subsidentes. Assim, levando em consideração essa premissa, acredita-se que a bacia do rio Chapecó possua sim influência tectônica, mesmo que muito sutil, sendo que as áreas com maiores espessuras de formações superficiais constitua um bloco subsidente, já as mais dissecadas blocos ascendentes.

Ao realizar uma análise integrada dos resultados fluviomorfométricos somados as bases geológicas, estruturais e profundidades de solos, foi possível dividir a bacia do rio Chapecó (Figura 7) em 3 compartimentos fluviomorfométricos: $\mathrm{C} 1, \mathrm{C} 2, \mathrm{C} 3$. O quadro 1 apresenta as características de cada um deles. Essa é a primeira aproximação da compartimentação da bacia em estudo, ainda é necessário uma análise mais detalhada, pois acredita-se que em $\mathrm{C} 1$ possa ser compartimentado em dois sub-compartimentos.

Mesmo com autores como Lima (2013), que discordam da metodologia aplicada, os estudos de perfil longitudinal e metodologias utilizadas são de grande relevância aos nos estudos dos cursos fluviais. Estas metodologias, apesar de antigas e desenvolvidas para áreas tectonicamente ativas, vêm sendo empregadas no Brasil, localizado em uma área tectonicamente estável, em diversos estudos geomorfológicos com grande eficácia, como por exemplo nos trabalhos de Fujita et. al, (2011), Martinez et al., (2011), Santos et. al. (2011) Guedes et al. (2006), Fujita (2014), pois seus resultados auxiliam no entendimento da configuração do sistema fluvial e de sua evolução geomorfológica, pois refletem as influências geológicas, tectônicas e de mudanças de nível de base.

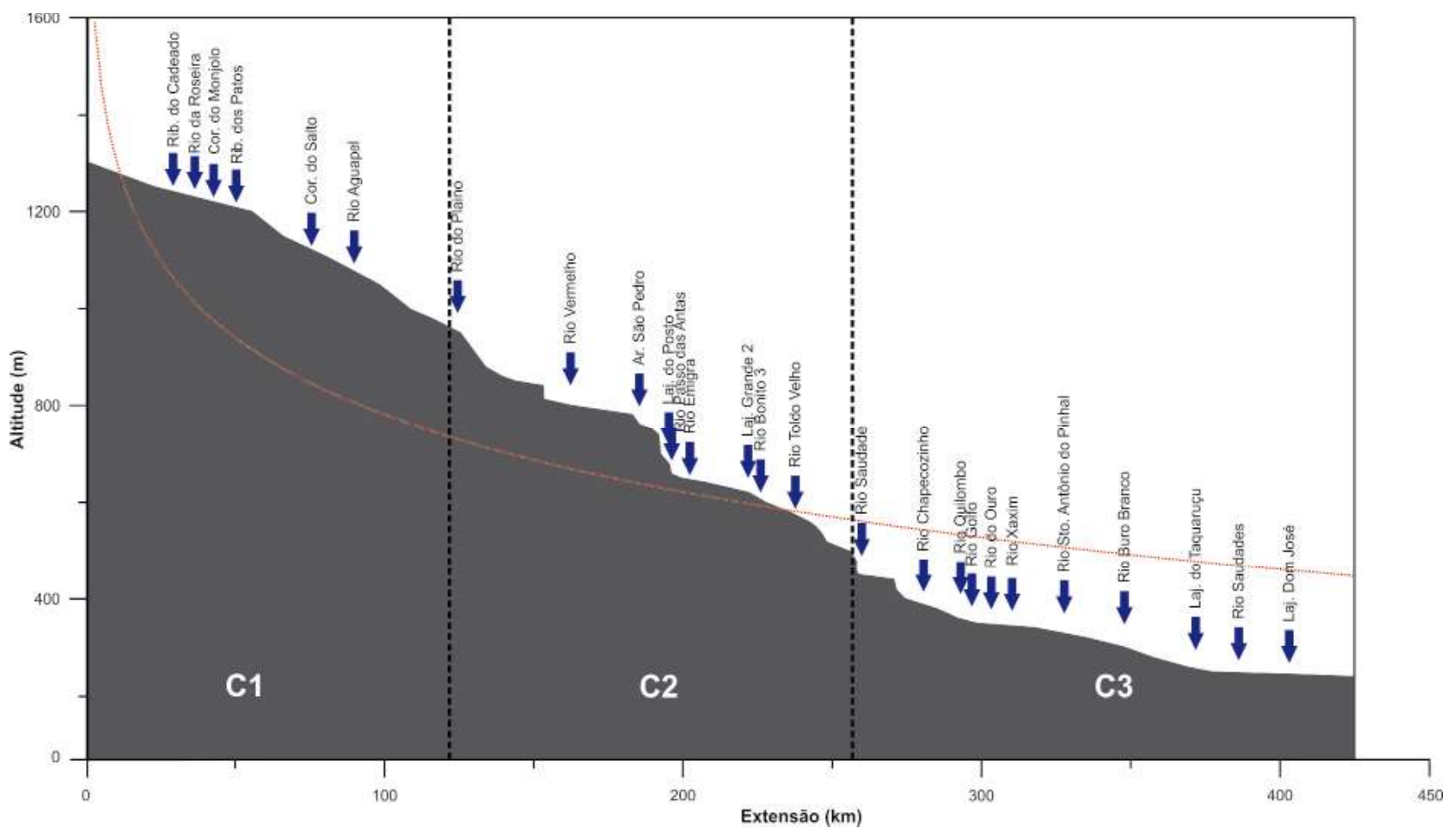

Figura 7 - Compartimentação fluviomorfométrica da Bacia do rio Chapecó, integração do perfil longitudinal e seus afluentes. 
Quadro 1: Quadro resumo das principais características dos compartimentos da bacia do rio Chapecó.

\begin{tabular}{|c|c|}
\hline COMPARTIMENTO & CARACTERÍSTICAS \\
\hline $\mathrm{C} 1$ & 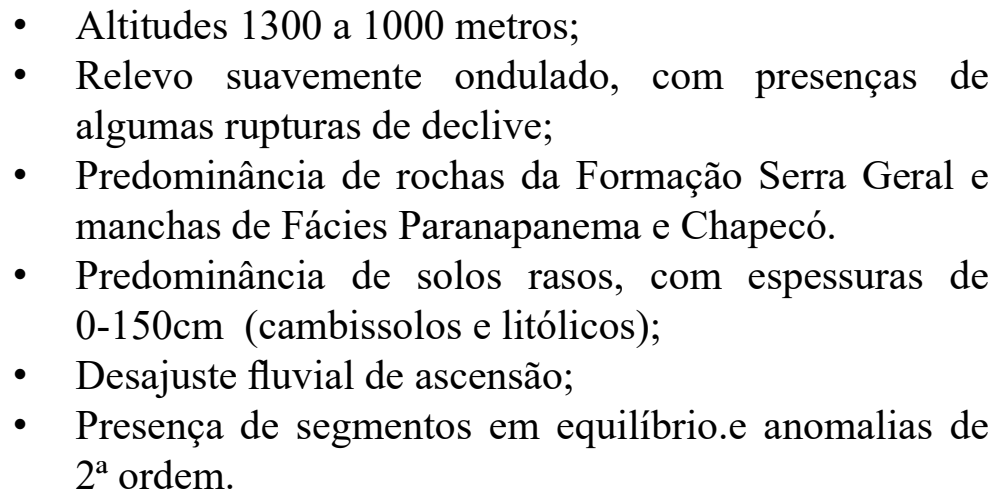 \\
\hline $\mathrm{C} 2$ & $\begin{array}{l}\text { - Altitudes } 1000 \text { a } 440 \text { metros; } \\
\text { - Localizado entre os rios do Plaino e da Saudade; } \\
\text { - Relevo suavemente a fortemente ondulado, marcado } \\
\text { pela seqüência de ressaltos topográficos de proporções } \\
\text { significativas, como por exemplo as Cataratas do rio } \\
\text { Chapecó, } \\
\text { - Predominância de rochas das Fácies Paranapanema, } \\
\text { Chapecó e Campos Novos } \\
\text { - Predominância de solos mais espessos (latossolos e } \\
\text { - Dambissolos); } \\
\text { - Presajuste fluvial de ascensão em sua maioria ; }\end{array}$ \\
\hline $\mathrm{C} 3$ & $\begin{array}{l}\text { - Altitudes } 440 \text { a } 240 \text { metros; } \\
\text { - Relevo fortemente ondulado; } \\
\text { - Predominância de rochas da Fáceis Campos Novos e } \\
\text { Campo Erê e depósitos aluvionares; } \\
\text { - Predominância de solos rasos a espessos (cabissolos e } \\
\text { latossolos); } \\
\text { - Desajuste fluvial de subsidência; } \\
\text { - Presença de segmentos em equilíbrio., anomalias de } 2^{\text {a }} \\
\text { e } 1^{\text {a }} \text { ordem. }\end{array}$ \\
\hline
\end{tabular}

\section{Conclusões}

Os resultados deste estudo foram obtidos a partir da sistematização dos resultados morfométricos, delineados no perfil longitudinal e aplicação do Índice de Hack, para o rio Chapecó e seu afluente Chapecozinho, pertencentes ao sistema fluvial Uruguai. Diante dos resultados apresentados ao longo deste trabalho, puderam-se chegar às seguintes conclusões:

Os canais fluviais estudados encontram-se em desajustes fluviais de ascensão e subsidência. O rio Chapecozinho apresenta um segmento em equilíbrio que corresponde as áreas das formações superficiais em elaboração, descritas por Paisani et al. (2008);

Os desajustes fluviais e as anomalias de $2^{\mathrm{a}}$ ordem estão relacionadas a áreas de confluência de canais, mudanças litológicas e também influência estrutural;

As anomalias de $1^{a}$ ordem identificadas estão vinculadas a forte controle estrutural. A presença das 


\section{Compartimentação Fluviomorfométrica da Bacia Hidrográfica do Rio Chapecó, Primeira Aproximação}

anomalias nas regiões de saltos e cachoeiras, somadas as áreas de solos mais espessos remetem a processos neotectônicos;

Como primeira aproximação a bacia do rio Chapecó foi dividida em 3 compartimentos $\mathrm{C} 1, \mathrm{C} 2, \mathrm{C} 3$. Ainda é necessário a continuidade do trabalho para maior detalhamento dessa compartimentação, uma vez que há possibilidades de $\mathrm{C} 1$ ser subdividida. Até então, $\mathrm{C} 1$ e $\mathrm{C} 3$ constituem blocos ascendentes e $\mathrm{C} 2$ um bloco subsidente.

\section{Referências Bibliográficas}

ACKLAS Jr. R.; ETCHEBEHERE, M. L. C.; CASADO, F. C. Análise de perfis longitudinais de drenagens do Município de Guarulhos para a detecção de deformações neotectônicas. Revista UnG - Geociências, ano 6, n. 8, p. 64-78, 2003.

BARTORELLI, A. As principais cachoeiras da Bacia do Paraná e sua relação com alinhamentos tectônicos. 1997. 2v $190 \mathrm{f}$. Tese (Doutorado em Geologia Regional), IGCE, UNESP, Rio Claro, 1997.

CARLSTON, C.W., Longitudinal slope characteristics of rivers of the mid-continent and the Atlantic east Gulf slopes. Bulletin of the International Association of Scientific Hydrology. XIV, 4, 1969.

ETCHEBEHERE, M.L., SAAD, A.R., FÚlVARO, V.J., PERINOTTO, A.J., Detection of neotectonic deformations along the Rio do Peixe Valley, Western São Paulo State, Brazil, based on the distribution of late Quaternary allounits. Revista Brasileira de Geomorfologia. Ano 6, n 1, 109-114., 2004.

ETCHEBEHERE, M.L.C. Terraços neo-quaternários no vale do rio do Peixe, planalto ocidental paulista: Implicações estratigráficas e tectônicas. Tese de doutorado, UNESP, Instituto de Geociências e Ciências Exatas, Rio Claro, SP, 2000.

FUJITA, R. H.; GON, P. P.; STEVAUX, J. C.; SANTOS, M. L.; ETCHEBEHERE, M. L. C. Perfil longitudinal e a aplicação do índice de gradiente (RDE) no rio dos Patos, bacia hidrográfica do rio Ivaí, PR. Revista Brasileira de Geociencias,. 2011.

FUJITA, RH. Geomorfologia e evolução quaternária da Calha do Alto rio Paraná, no segmento livre de barramentos, entre os reservatórios de Porto Primavera e Itaipu.Tese (Doutorado) Instituto de Geociências e Ciências Exatas/Universidade Estadual Paulista Júlio de Mesquita Filho. Rio Claro, SP, 2014. 110p.

FUJITA, RH. Geomorfologia e evolução quaternária da Calha do Alto rio Paraná, no segmento livre de barramentos, entre os reservatórios de Porto Primavera e Itaipu.Rio Claro, SP, 2014. Tese (Doutorado) - Instituto de Geociências e Ciências Exatas/Universidade Estadual Paulista Júlio de Mesquita Filho.

GORNITZ, V., AND L. SEEBER., Vertical crustal movements along the East Coast, North America, from historic and Late Holocene sea level data. Tectonophysics, 178, 127-150, 1990.

GUEDES, I. C. Aplicação de análise flúvio-morfométrica na bacia hidrográfica do rio Santo Anastácio, SP, para detecção de deformações neotectônicas. Dissertação de mestrado, Mestrado em Análise Geoambiental, Universidade Guarullhos, Guarulhos, SP, p.118. 2008.

GUEDES, I. C.; SANTONI, G. C.; ETCHEBEHERE, M. L. C.; STEVAUX, J. C.; MORALES, N.; SAAD, A. C. Análise de perfis longitudinais de drenagens da bacia do rio Santo Inácio(SP) para detecção de possíveis deformações neotectônicas. Revista UNG - Geociências, v. 5, nº 1, 75-102, 2006.

HACK, J.T. Stream-profile analysis and stream-gradient index. U.S. Geol. Survey, Jour. Research, 1(4): 421-429, 1973.

LARUE, J.-P., Effects of tectonics and lithology on long profiles of 16 rivers of the southern Cantral Massif border between and Aude and Orb (France). Geomorphology, 93, 343-367, 2008.

LIMA, AG., Índice de gradiente de canal: significados e diretrizes para aplicação. Brazilian Geographical Journal: Geosciences and Humanities research medium,Ituiutaba, v. 4, n. 2, p. 680 692, jul./dec. 2013.

MARTINEZ, M. Aplicação de parâmetros morfométricos de drenagem na bacia do rio Pirapó: O perfil longitudinal. Dissertação( Mestrado em análise regional e ambiental)Departamento de Geografia, Universidade Estadual de Maringá, Maringá, 2004.,

MARTINEZ, M., HAYAKAWA, E.H., STEVAUX, J.C., PROFETA, J.D., , SL index as indicator of anomalies in the longitudinal profile of Pirapó River. Geociências, São Paulo, UNESP, v.30, n.1, p.63-76, 2011.

McKEOWN, F.A. et al., Analysis of stream-profile data and inferred tectonic activity, Eastern Ozark Mountain region. Denver. U.S. Geol. Survey Bull. 1807, 39 p., 1988.

PAISANI, JC; PONTELLI, ME; ANDRES, J., Superfícies aplainadas em zona morfoclimática subtropical úmida no Planalto Basáltico da Bacia do Paraná (SW Paraná/ NW Santa Catarina): Primeira Aproximação. Geociências, São Paulo, UNESP, v.27, n.4 p.541-553, 2008.

PANDOLFO, C.; BRAGA, H.J.; SILVA JÚNIOR, V.P.; MASSIGNAN, A.M.; PEREIRA, E.S.; THOMÉ, V.M.R; 
Fujita R. H. et al.

VALCI, F.V. Atlas climatológico do Estado de Santa Catarina. Florianópolis: Epagri, 2002. CD-ROM.

SANTOS, LFF; GUEDES, IC; ETCHEBEHERE, MLC. Análise Neotectônica do Pontal do Paranapanema (SP) mediante aplicações de parâmetros fluviomorfométricos. Geociências v.30; n.4; p.491-507, 2011.
TEIXEIRA, H.; MARTINS, A.; CUNHA, P.; GOMES, A., 2013. A identificação automática de knickpoints nas bacias dos rios Poio e Cabril (bacia do Tâmega): vantagens e comparação de resultados. VI CONGRESSO NACIONAL DE GEOMORFOLOGIA - Coimbra, 2013 Atas/Proceedings - ISBN 978-989-96462-4-7 183 